\title{
The first fossil skull of Chelus \\ (Pleurodira: Chelidae, Matamata turtle) from the early Miocene of Colombia
}

\author{
Edwin A. Cadena and Carlos A. Jaramillo
}

\begin{abstract}
Here we describe the first fossil skull so far known for the turtle genus Chelus from the early Miocene ( 16 m.y.), Castilletes Formation, Alta Guajira Peninsula, Cocinetas basin, Colombia. The skull is partially preserved, including most of the basicranium (pteygoid-bassioccipital bones) and the roof elements including the parietal, pterygoid and portions of the squamosal, supraoccipital and the most dorsal quadrate. The skull is preserved in three dimensions, without evidence of crushing, allowing the observation of the internal braincase morphology using microcomputer tomography. Comparisons with the skull of the only extant species for the genus Chelus fimbriata (Matamata turtle) allow us to conclude that for the last 16 million years the morphology of the skull for this genus has remained almost unvarying, with only a slightly higher compression of the most anterior braincase exhibited by the extant species. Due to its fragmentary condition, a more refined identification beyond the genus (Chelus sp.) is not possible; however, the overall skull design indicates that the fossil species could also have had the same ecological and dietary adaptations as its extant relative.
\end{abstract}

Edwin A. Cadena. Center for Tropical Paleoecology and Archaeology, Smithsonian Tropical Research Institute, Balboa, Ancon, Panama, and Senckenberg Museum, Department of Paleoanthropology and Messel research,603025 Frankfurt, Germany cadenachelys@gmail.com

Carlos A. Jaramillo. Center for Tropical Paleoecology and Archaeology, Smithsonian Tropical Research Institute, Balboa, Ancon, Panama jaramilloc@si.edu

Keywords: Chelidae; Testudines; Colombia; South America; La Guajira

\section{INTRODUCTION}

The extant freshwater turtle species Chelus fimbriata Schneider, 1783 (Matamata turtle) from tropical South America is one of the most bizarre turtles, and the only living species in the genus. It is characterized by a very flat skull with a rugose dorsal bone surface among pleurodiran turtles, and a carapace with three lines of almost parallel knobs. The turtle inhabits shallow depths of slow-moving or still waters of the Amazon and Orinoco basins, 

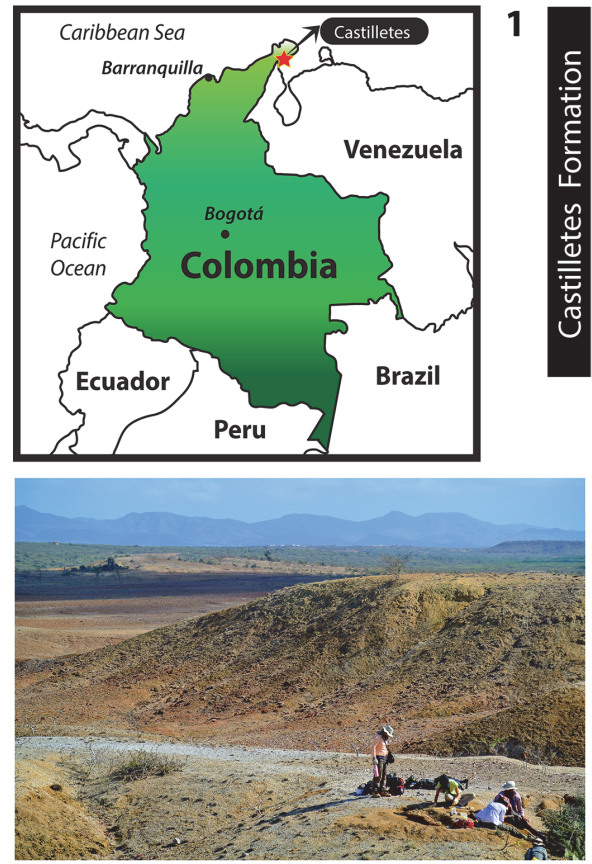

1

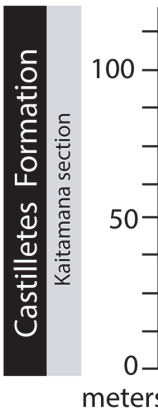

3

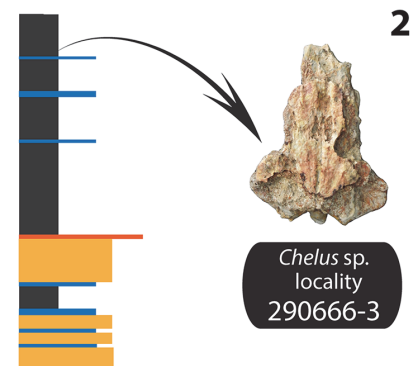

2

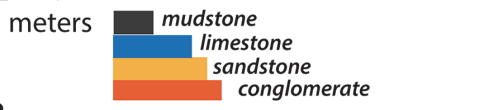

4

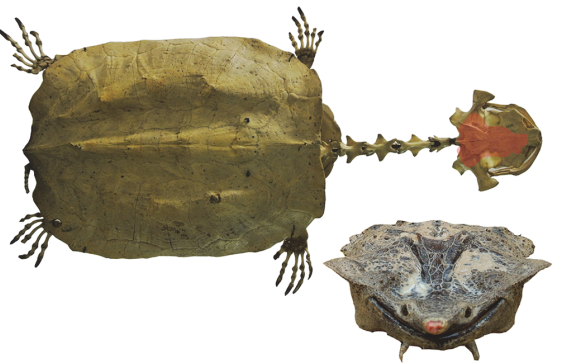

FIGURE 1. Geographical and stratigraphical occurrence of Chelus sp. MUN-STRIdbid 38473. 1, map of the northernmost portion of South America, showing the location of Castilletes, on the Guajira Peninsula of Colombia. 2, stratigraphic column for the lower segment of the Castilletes Formation, Kaitamana section, including the horizon where Chelus sp. MUN-STRI-dbid 38473 was found, redrawn from Moreno et al. (2015). 3, landscape photograph of the locality where Chelus sp. MUN-STRI-dbid 38473 was found. 4, complete skeleton of Chelus fimbriata NMW 1859, orange shadowed area in the skull, represents the area preserved in the fossil Chelus sp. MUN-STRI-dbid 38473, down is the anterior view of the head of Ch. fimbriata (photo credit, Stuart Hamilton).

and it has a mostly carnivorous diet (Pritchard and Trebbau, 1984; Pritchard, 2008). The morphology of the skull of $C$. fimbriata was described in detail by Gaffney (1977), and more recently its cranial musculature and its feeding mechanisms were described by Lemell et al. (2010). This study suggested that the flat configuration of the skull, the size and shape of the muscles, the large ossified hyoid apparatus, and the well-distensible esophagus allow $C$. fimbriata to produce an enormous suction force to inhale its prey.

The fossil record of Chelus is restricted to shell material and is represented by two species: C. lewisi Wood, 1976, known from the late Miocene, Urumaco Formation of Venezuela (SánchezVillagra and Scheyer, 2010), and C. colombiana Wood, 1976, from the middle to late Miocene, Villavieja Formation in Colombia, the late Miocene of Estado do Acre of Brazil, and the early Miocene Barzalosa Formation (earliest record for the genus) in Colombia (Wood, 1976; Bocquentin and Rodrigues dos Santos, 1989; Cadena et al., 2008). Recently, shell material of C. colombiana and an indeterminate species, potentially related to $C$. lewisi were reported for the early Miocene $(\sim 16.2$ m.y.), Castilletes Formation, Alta Guajira Peninsula in the Cocinetas basin of Colombia (Cadena and Jaramillo, 2015) (Figure 1.1-3). Also from this locality we describe here the first fossil skull for Chelus. Using micro computed tomography, we compared the morphological differences between the fossil and the extant representative of this genus, discussing the evolutionary and ecological implications.

\section{MATERIAL AND METHODS}

Three specimens of Chelus fimbriata (see Figure 1.4, for general body plan) were used for comparisons with the fossil skull described here. These specimens allow the study not only of the exterior morphology of the skull, but also of the braincase. The head of a wet preserved specimen of $C$. fimbriata (SM 57977) was dissected following the steps described by Wyneken (2001), and most of the roof skull bones were removed. A dry preserved skull SM 37178 (a male) and the fossil partial skull MUN-STRI-dbid 38473 were scanned using TomoScope HV 500 at the Hochschule Deggendorf, Bavaria, Germany, with the following setup parameters: voltage $190 \mathrm{kV}$, exposure time of $0.3 \mathrm{~s}$, cur- 

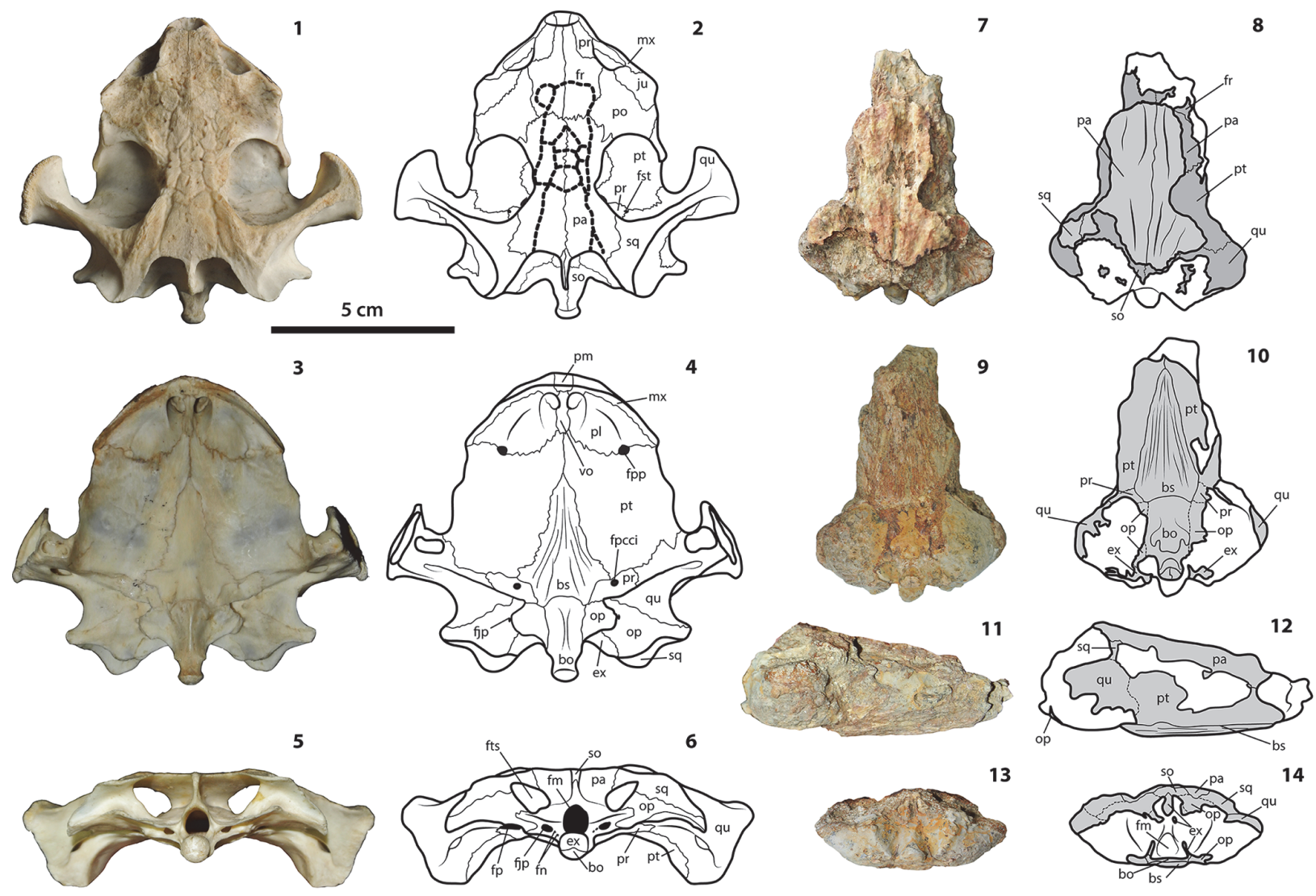

FIGURE 2. Skulls of Chelus fimbriata SM 37178 and Chelus sp. UNT-STRI-dbid 38473. Photographs and interpretative drawings. Chelus fimbriata SM 37178. 1-2, dorsal view; 3-4, ventral view; 5-6, posterior view. Chelus sp. MUNSTRI-dbid 38473 fossil from Castilletes Formation, Colombia. 7-8, dorsal view; 9-10, ventral view; 11-12, right lateral view; 13-14, posterior view. Abbreviations: bo, basioccipital; bs, basisphenoid; ex, exoccipital; fjp, foramen jugulare posterius; fm, foramen magnum; fn, foramen nervi hypoglossi, fp, fenestra postotica; fpcci, foramen posterior canalis caroticus cerebralis; fpp, foramen palatinum posterior; fr, frontal; fst, foramen stapedio temporalis; fts, fossa temporalis superior; ju, jugal; mx, maxilla; op, opisthotic; pa, parietal; pf, prefrontal; pl, palatine; pm, premaxilla; po, postorbital; pr, prootic; pt, pterygoid; qu, quadrate; so, supraoccipital; sq, squamosal; vo, vomer. Dotted line in 2 indicates sulci of skull scutes. Light grey areas in 8 indicate preservation of the dorsalmost surface of the bones. Scale bar applies for all figures.

rent 220 microamps, voxel size $2.5 \mu \mathrm{m}$ and 1200 steps. CT images were processed and analyzed using VGStudioMax version 2.2. A third specimen used for comparison was taken from the Digital Morphology library (www.digimorph.org/specimens/Chelus_fimbriatus/head/) specimen UMA R1376 (Gaffney, 2002).

\section{Institutional Abbreviations}

MUN, Museo de la Universidad del Norte, Barranquilla, Atlántico, Colombia, the repository of the specimens; SM, Senckenberg Museum of Natural History, herpetological collection, Frankfurt, German; STRI-dbid, Smithsonian Tropical Research Institute, geological sample collection, Balboa, Ancon, Panama; web access to this database is available at http://biogeodb.stri.si.edu; UMA, Mas- sachusetts Museum of Natural History, Amherst, MA, USA.

\section{SYSTEMATIC PALAEONTOLOGY}

\author{
Infraorder PLEURODIRA Cope, 1864 \\ Family CHELIDAE Gray, 1825 \\ Genus CHELUS Dumeril, 1806
}

Included species. Chelus fimbriata Schneider, 1783 (extant, see Figure 2.1-6), Chelus colombiana Wood, 1976 (sensu Cadena et al., 2008) (fossil), Chelus lewisi Wood, 1976 (fossil).

Revised diagnosis. Combined from Gaffney (1977) and Cadena et al. (2008). Chelus differs from all other chelid turtles by: (1) absence of nasal bones; (2) broad exposure of the prefrontals dorsally along the apertura narium; (3) anterior exten- 
sion of the pterygoid into the apertura narium interna, often separating the vomer from the palatines; (4) extreme flattening of the dorsal skull, particularly in the center; (5) extreme lateral projection of the cavum tympani; (6) medial process of jugal and postorbital lying entirely on dorsal surface of skull; (7) maxilla very reduced in exposure on triturating surface, so that palatine bears lingual ridge; (8) basisphenoid with a bone tissue pattern extremely acicular tapering anteriorly; (9) dorsal surface of the parietals and frontals very rugose, with very deep sulci for scutes; (10) costovertebral tunnel of the carapace; (11) dorsal surface of the carapace ornamented with three prominently raised, longitudinal ridges, one bearing five knobs and extending along the midline of carapace; (12) scar on ventral surface for contact of inguinal buttress restricted to costal 4 .

\section{CHELUS sp.}

Figure 2.7-14

Referred material. MUN-STRI-dbid 38473. Partially preserved skull.

Locality, horizon, and age. Chelus sp. MUNSTRI-dbid 38473 comes from the lower segment of the Castilletes Formation, locality number 2906663 (Braincase), Kaitamana section, dated as $\sim 16.2$ m.y., radiometric age for the lower segment (Moreno et al., 2015).

Description and remarks. Chelus sp. MUN-STRIdbid 38473 is a partially preserved skull with a maximum length of $67 \mathrm{~mm}$, maximum width of 50 $\mathrm{mm}$, and maximum height of $27 \mathrm{~mm}$ (all measurements as preserved). On the dorsal surface of the skull, most of the parietal bone is preserved exhibiting the characteristic dorsal surface corrugation as in the extant Chelus fimbriata; this sculpturing pattern is related to the abundant number of skull scutes with very deep sulci, and irregular in number and shapes.

At the most anterior edge of both parietals the contact with the frontals is at least visible at the most right lateral portion of the skull; however, the frontals are only preserved as a very thin layer of the bone (the most ventral portion of bones). Portions of the pterygoids are also preserved as very thin layers of bone, highly eroded, with their medial contacts with the parietals hidden in dorsal view occurring under the most lateral portions of parietals, as in C. fimbriata. On the left side of the skull, a small portion of the squamosal bone is preserved, and a portion of the supraoccipital bone at the most posterior medial region. On the ventral surface, the basisphenoid has the characteristic elongated dagger shape, as in C. fimbriata, sepa- rating most of the pterygoids, which only have a short medial contact anteriorly. The basisphenoid is the only skull bone in Chelus sp. MUN-STRIdbid 38473 with clearly delimited sutural contacts and shape. Direct examination of skulls of $C$. fimbriata (Appendix 1) and MUN-STRIdbid 38473 described here, allow us to conclude that the basisphenoid bone for the genus Chelus has a very distinct osteological pattern, where the bone tissue grows extremely acicular and tapering anteriorly; this pattern can also occur in the most medial portions of the pterygoid bone. The basioccipital, preserved only at its most dorsal extension, is similar to that in C. fimbriata, with a rectangular shape and with lateral acute tip processes facing posteriorly. Very small medial portions of opisthotics, prootics and exoccipitals are preserved; however, the sutural contacts with the basisphenoid and basioccipital are not clearly defined.

Braincase morphology. The CT images (Figure 3.1-7) show that most of the internal structure of the braincase, as well as the cavum tympani, are not well preserved and have mostly been eroded and filled by the rock matrix, which includes small bivalves and other shell (mollusc) fragments (Figure 3.3-4). However, some features are still well recognized, including the ascending dorsal portions of the pterygoids (Figure 3.2-3), the contact between the frontal and parietals, and the contact between the parietals and the supraoccipital (Figure 3.4-5). The ascending lateral processes of the basisphenoid are also well delimited (Figure 3.6), as are portions of the descending ventral process of the parietal (Figure 3.7). In all morphological features and sutural contacts, the fossil skull of Chelus $\mathrm{sp}$. described here, resembles the skull of the extant $C$. fimbriata, except for the size of the endocranium, see below.

\section{DISCUSSION}

\section{Endocranium}

Using the CT images obtained for the fossil Chelus sp. MUN-STRI-dbid 38473 (Appendices 24), the extant $C$. fimbriata SM 37178 (Appendices 4-7), the specimen available at Digimoprh C. fimbriata UMA R-1376, and the sectioned dry skull of C. fimbriata SM 57977, and considering that the basisphenoid is the only complete and well delimited bone for the fossil skull, we defined two points for measuring the height of the endocranium and explore the differences between extant and the fossil Chelus (Figures 4 and 5). The first point of measurement is at the sutural contact between the 

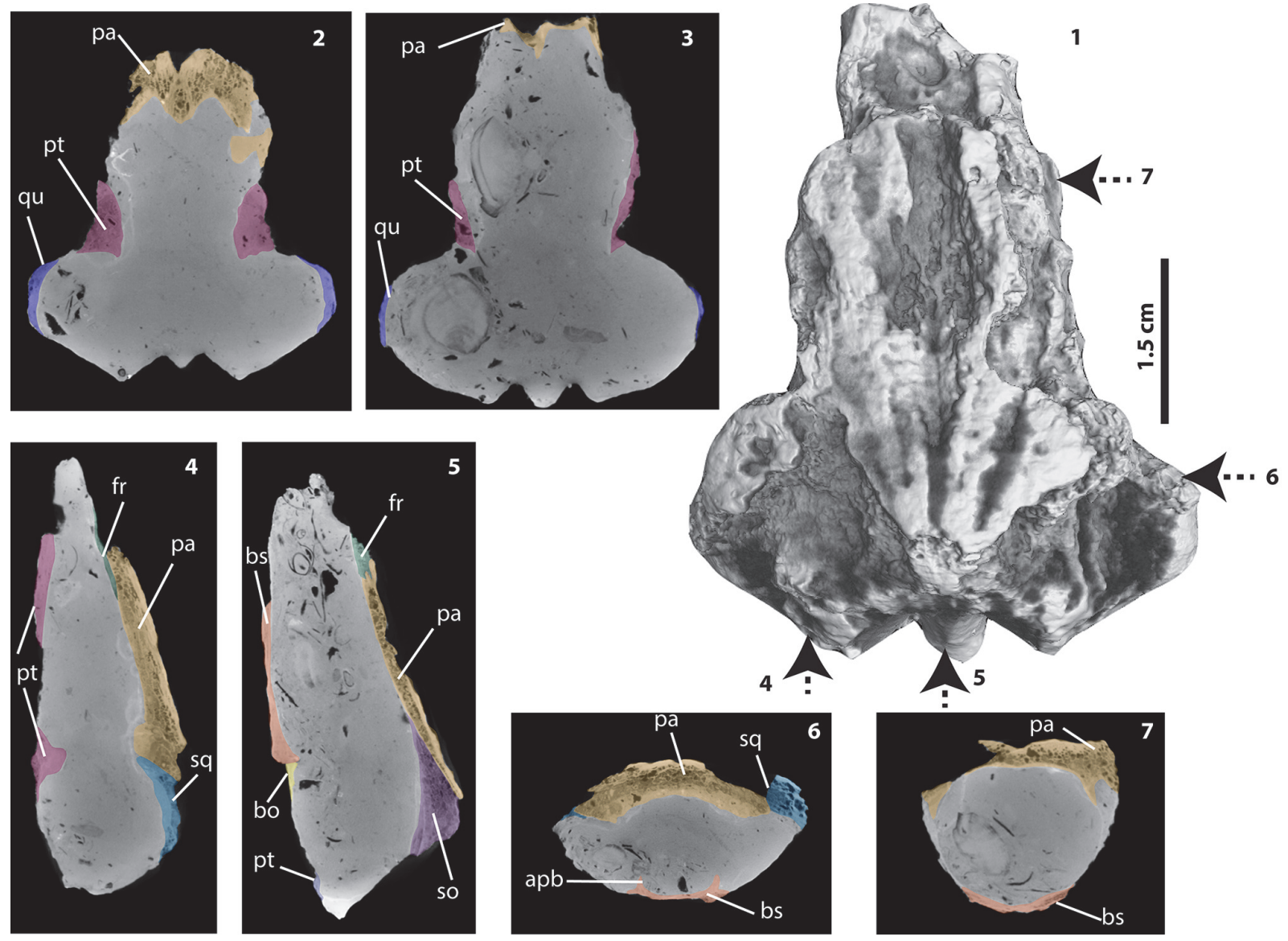

FIGURE 3. CT images of Chelus sp. MUN-STRI-dbid 38473. 1, skull in dorsal view, arrows indicate the position of the cuts shown in 4-7. 2, horizontal cut on the lower portion of the skull, anterior to the foramen magnum. 3, horizontal cut at the level of the widest portion of the skull. 4, sagittal cut on the left portion of the skull. 5, sagittal cut at the midline of the skull. 6, coronal cut very close to the level of the basisphenoid-basioccipital contact. 7, coronal cut on the anterior portion of the skull. Abbreviations are as in Figure 2, plus apb (anterior process of basisphenoid).

basisphenoid and basioccipital and the second at the most anterior tip of the basisphenoid (see Figure 4 for measurements details). From this, we found that the anterior height of endocranium cavity is smaller relative to the posterior height in extant specimens of Ch. fimbriata, compared to Chelus sp. (Figures 4 and 5). This feature is conservative through ontogeny, as SM 57977 is a juvenile, and UMA R-1376 is younger, attribution based not only on the size of the skull, but also on the level of ossification of sutural bone contacts. There is not evidence of disarticulation or dislocation of bones for the fossil skull, which has retained almost perfectly the bilateral symmetry (see Figure $2.10,2.14)$, instead, the bone surface delimitating the endocranium cavity dorsally and ventrally is smooth as in the extant specimens, indicating that alteration of the bone thickness or of the endocranial cavity due to abrasion or erosion was minimal. We point out here also that the variations observed in the height of the endocranium between the fossil and extant Chelus could correspond to intraspecific variability, and that more specimens of Ch. fimbriata from different geographical populations, ontogenetic stages and sex should be included in future studies in order to support this hypothesis. Similar as it has been done with the variation in the shell morphology of Ch. fimbriata, between Orinoco and Amazonas basin populations (Sanchéz-Villagra et al., 1995).

\section{Paleoecological Implications}

In morphology, bone histology, and size, the fossil Chelus sp. from the Castilletes Formation is almost identical to the extant adult skull of $C$. fimbriata (SM 37178). These similarities indicate that the design of the flat head, which prevents a bow wave during fast forward movement of the strike, when the turtle is catching and suctioning the pray (Lemell et al., 2010), has persisted for at least the 

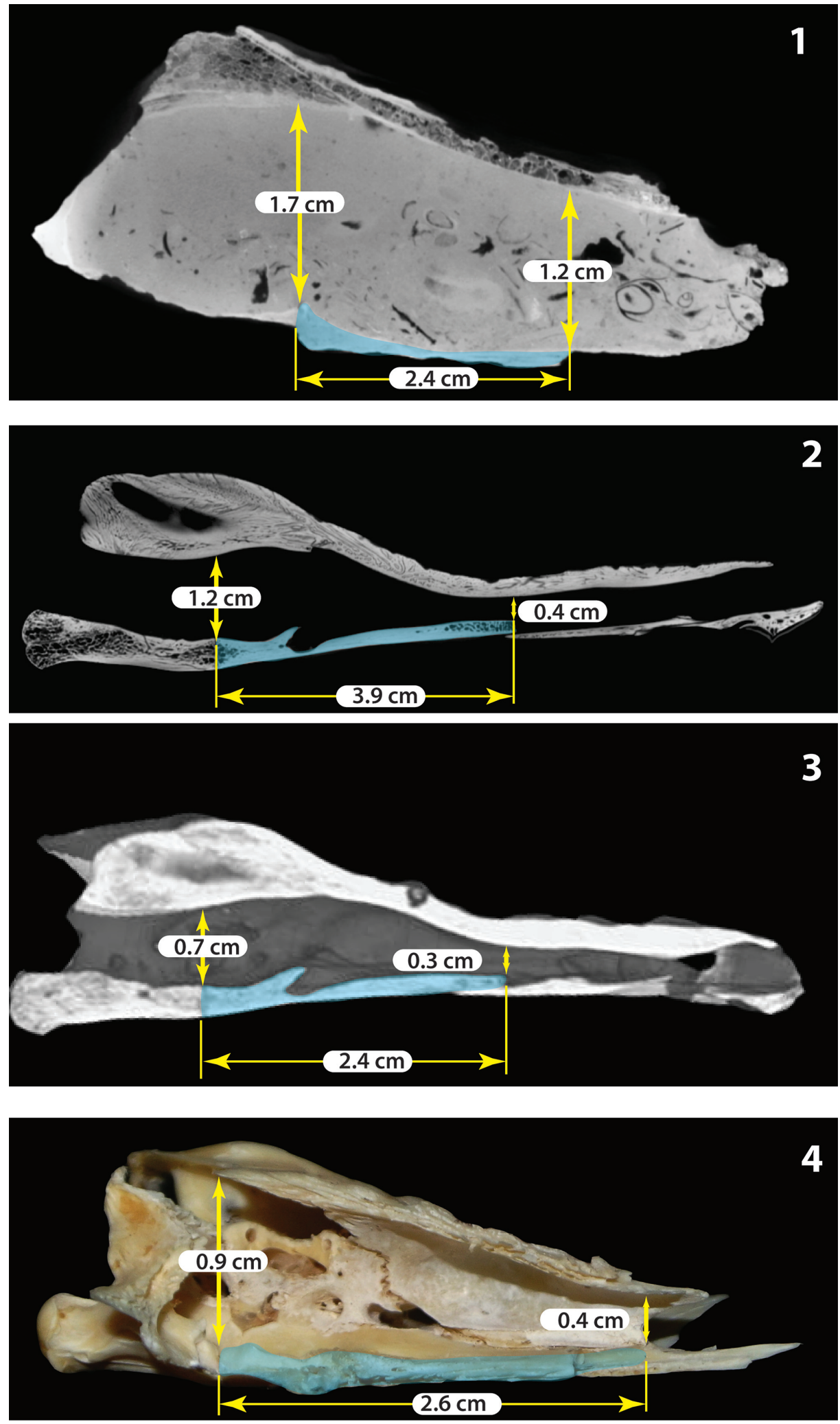

FIGURE 4. CT images of Chelus sp. and the extant $C$. fimbriata in sagittal view. These figures show the difference in the height of the endocranium between the fossil skull described here and juveniles and adults of the extant representative of Chelus; all cuts are located at the midline of the skull. 1, Chelus sp. MUN-STRI-dbid 38473 (adult); 2, C. fimbriata SM 37178 (adult); 3, C. fimbriata UMA R-1376 (hatchling-juvenile?); 4, C. fimbriata SM 57977 (juvenile). The basisphenoid bone is delimited by light blue color. 


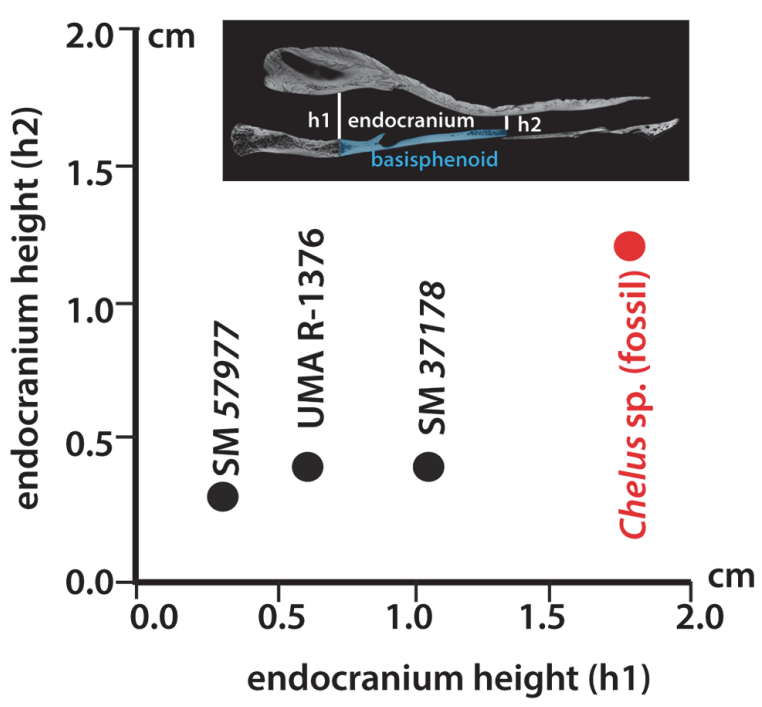

FIGURE 5. Comparison between height of the endocranium at the anterior (h1) and posterior (h2) end of the basisphenoid for three extant Chelus fimbriata specimens (black dots) vs the fossil Chelus sp. described here (red dot).

last 16 million years. The higher anterior portion of the endocranial cavity exhibited by the fossil Chelus sp., which corresponds to the space of the cranium occupied principally by the olfactory bulb as seen in the brain reconstructions for other turtles (Carabajal et al., 2013), could indicate a slightly larger olfactory bulb compared to the extant representative. However, without documentation or illustrations of the brain of extant species, we are unable to test this hypothesis at this point. To explore potential physiological implications size variation in the anterior endocranium, we encourage a future study of the brain of the extant species, C. fimbriata, which will contribute to a better understanding not only of its physiology and ecology, but also of the evolution of chelid turtles.

Environmental reconstructions for the lower segment of Castilletes Formation (Moreno et al., 2015), where the fossil skull of Chelus sp. was found, suggest estuarine-brackish environments with a marked marine influence. These environments are within the wide spectrum of habitats documented for the extant $C$. fimbriata (Pritchard, 2008).

Considering the high degree of fragmentation exhibited by the skull, however, we do not exclude the possibility of transport before burial; it is therefore possible that the depositional environment interpreted does not necessarily correspond to the original habitat. The presence of Chelus in the
Castilletes Formation also indicates a profound transformation of the landscape of the Guajira peninsula over the past $16 \mathrm{~m} . \mathrm{y}$. The Cocinetas basin is today characterized by being extremely arid, with a prolonged dry season ( 11 months), dominated by xerophytic vegetation and lacking large rivers or year-round bodies of fresh water. Chelus fimbriata, however, requires the shallow depths of slow-moving or still waters all year round to survive (Pritchard, 2008). This contrast suggests that a major change in the Cocinetas landscape occurred during the late Neogene that led to the extant aridification of the region.

\section{ACKNOWLEDGMENTS}

Funding for this work was provided by Smithsonian Institution, National Geographic Society, Anders Family, Universidad del Norte, University of Zurich, and Alexander Von Humboldt Foundation. We thank to all participants of the Castilletes project for your help during fieldwork: A. Hendy, R. Sanchéz, F. Moreno, C. Martinez, C. Vallejo, G. Ballen, J. Moreno, C. Súarez, J. Carrillo, J.D. Carrillo, N. Pérez, C. Montes, K. Jimenez, J. Luque, A. Cárdenas, J. Escobar, N. Hoyos, D. Delgado, M. Sanchéz-Villagra. Thanks to K. Smith and P. Hornberger for helping in the acquisition and processing of the micro CT data. Thanks to two anonymous reviewers for their comments and suggestions to improve this manuscript. Specials thanks go to $\mathrm{C}$. Rosero, L. Londoño, M. Barreto, El Grillo and the Wayuu community of Castilletes for your help on the logistics and realization of the fieldwork seasons.

\section{REFERENCES}

Bocquentin, V. and Rodrigues dos Santos, J. 1989. Ocorrência de Chelus colombiana (Chelonii, Chelidae) no Mioceno superior do Estado do Acre, Brasil, p. 439-446. In Paleontologia SBd (ed.), XI Congresso Brasileiro de Paleontologia, Curitiba.

Cadena, E.A., Jaramillo, C.A., and Páramo, M.E. 2008. New material of Chelus colombiana (Testudines; Pleurodira) from the Lower Miocene of Colombia. Journal of Vertebrate Paleontology, 28:1206-1212.

Cadena, E.A. and Jaramillo, C.A. 2015. Early to middle Miocene turtles from the northermost tip of South America: Giant testudinids, chelids, and podocnemidids from the Castilletes Formation, Colombia. Ameghiniana, 52:188-203.

Carabajal, A.P., Sterli, J., Müller, J., and Hilger, A. 2013. Neuroanatomy of the marine Jurassic turtle Plesiochelys etalloni (Testudinata, Plesiochelyidae). PLoS ONE 8: e69264: doi:10.1371/ journal.pone.0069264. 
Cope, E.D. 1864. On the limits and relations of the Raniformes. Proceedings of the Academy of Natural Sciences of Philadelphia, 16:181-183.

Dumeril, A.M. 1806. Zoologie analytique, ou méthode naturelle de classification des animaux. Allais Librairie, Paris.

Gaffney, E.S. 1977. The side-necked turtle Family Chelidae: A theory of relationships using shared derived characters. American Museum Novitates, 2620:1-28.

Gaffney, E.S. 2002. Chelus fimbriatus (On-line), Digital Morphology. Accessed April 25, 2014 at http:// digimorph.org/specimens/Chelus_fimbriatus/head/.

Gray, J.E. 1825. A synopsis of the genera of reptiles and amphibia, with a description of some new species. Annals of Philosophy, 10:193-217.

Lemell, P., Beisser, C.J., Gumpenberger, M., Sneldwerwaard, P., Gemel, R., and Weisgram, J. 2010. The feeding apparatus of Chelus fimbriatus (Pelurodira; Chelidae) - adaptation perfected? Amphibia-Reptilia, 31:97-107.

Moreno, J.F., Hendy, A., Quiroz, L.I., Hoyos, N., Jones, D., Zapata, V., Zapata, S., Ballen, G.A., Cadena, E.A, Cardenas, A., Carrillo, J., Carrillo, J.D., Delgado, D., Escobar, J.A., Martinez, J.I., Martinez, C., Montes, C., Moreno, J., Perez, N., Sanchez, R., Suarez, S.C., Vallejo-Pareja, M.C., and Jaramillo, C.A. 2015. Revised stratigraphy of Neogene strata in the Cocinetas Basin, La Guajira, Colombia. Swiss Journal of Palaeontology, doi: 10.1007/s13358-015-0071-4.

Pritchard, P.C.H. 2008. Chelus fimbriata (Schneider 1783)- Matamata turtle, p. 020.1-.10. In Rhodin,
A.G.J., Pritchard, P.C.H., van Dijk P.P., Saumure, R.A., Buhlmann, K.A., Iverson, J., and Mittermeier R.A. (eds.), Conservation Biology of Freshwater Turtles and Tortoises: A compilation Project of the IUCN/ SSC Tortoise and Freshwater Turtle Specialist Group, Chelonian Research Monographs 5. Chelonian Research Foundation, Florida.

Pritchard, P.C.H. and Trebbau, P. 1984. Turtles of Venezuela. Cornell University Press, Ithaca.

Sanchéz-Villagra, M.R., Pritchard, P.C.H., Paolillo, A., and Linares, O.J. 1995. Geographic variation in the matamata turtle, Chelus fimbriatus, with observations on its shell morphology and morphometry. Chelonian Conservation and Biology, 1:293-300.

Sánchez-Villagra, M.R. and Scheyer, T.M. 2010. Fossil turtles from the northern neotropics: the Urumaco sequence fauna and finds from other localities in Venezuela and Colombia, p. 56-57. In Sánchez-Villagra, M.R., Aguilera, O.A., and Carlini, A.A (eds.), Urumaco and Venezuelan Paleontology. Indiana University Press, Bloomington.

Schneider, J.G. 1783. Allgemeine Naturgeschichte der Schildkröten nebst einem systematischen Verzeichnisse der einzelnen Arten und zwey Kupfern. Müller, Leipzig.

Wood, R.C. 1976. Two new species of Chelus (Testudines: Pleurodira) from the Late Tertiary of northern South America. Breviora, 435:1-26.

Wyneken, J. 2001. The Anatomy of Sea Turtles. U.S. Department of Commerce NOAA Technical Memorandum, Miami. 


\section{APPENDIX 1.}

List of specimens of Chelus frimbiata directly examined by the senior author. Abbreviations: ICN, Instituto Colombiano de Ciencias Naturales, Universidad Nacional de Colombia, Bogotá, Colombia; MNHN, Muséum National d'Histoire Naturelle, Paris, France; NMW, Naturhistorisches Museum Wien, Vienna, Austria; Herpetological Collection, Senckenberg Museum, Frankfurt, Germany; USNM, Smithsonian National Museum of Natural History, Washington D.C., USA.

\begin{tabular}{|c|l|}
\hline ICN & \multicolumn{1}{|c|}{$1767,1776,1780,1781,6411$, D-75, and D-90 } \\
\hline \hline MNHN & $1930-365,1973-8381,1991-2581 B, 9406$, A5171, A5200, A9940 \\
\hline NMW & 1859,39830 \\
\hline SM & 57977,37178 \\
\hline USNM & $064154,117455,301989,301991,301992$ \\
\hline
\end{tabular}




\section{APPENDIX 2-7}

1, Sagittal cut of Chelus sp. MUN-STRI-dbid 38473 from appendix 2. 2, coronal cut of Chelus sp. MUNSTRI-dbid 38473 from Appendix 3. 3, horizontal cut of Chelus sp. MUN-STRI-dbid 38473 from Appendix 4. 4, sagittal cut of Chelus fimbriata SM 37178 from Appendix 5. 5, coronal cut of Chelus fimbriata SM 37178 from Appendix 6. 6, horizontal cut of Chelus fimbriata SM 37178 from Appendix 7. The figures below are from the online animations.Appendices 2-7 are available online in animated format at: palaeo-electronica.org/content/2015/1231-drimolen-makondo-fauna
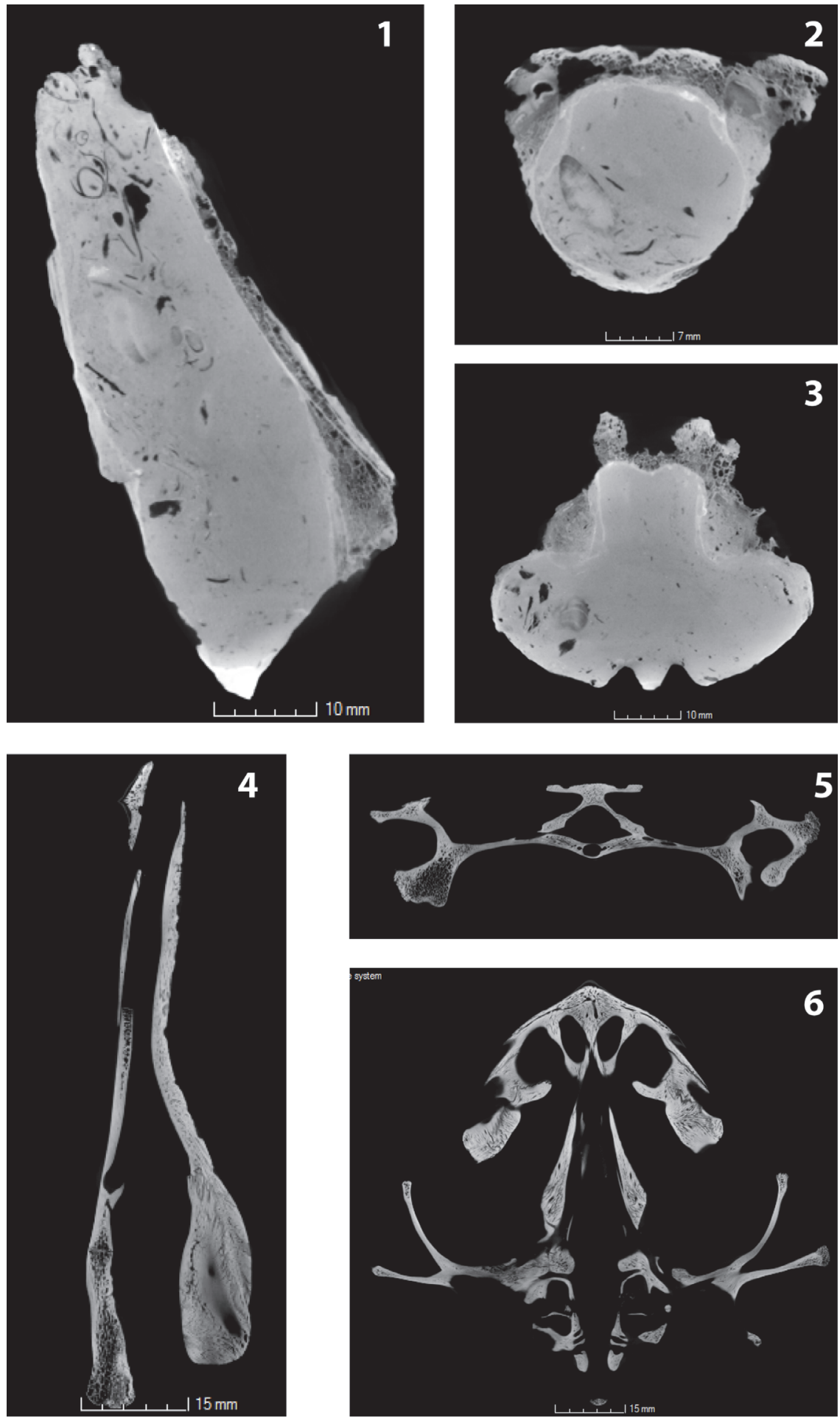